\title{
Early Elevated Leucocyte count predicts Neurodevelopmental Outcome in children with Neonatal Encephalopathy and remains altered at school age
}

Z. Zareen ${ }^{1-4}$, D. Sweetman 5 , M. Slevin 5 , V. Mc Eneaney ${ }^{1}$, Murphy JM ${ }^{5}$, E.J. Molloy ${ }^{1-5}$

\begin{abstract}
${ }^{1}$ Discipline of Paediatrics \& Trinity Translational Medicine Institute (TTMI), Trinity College, the University of Dublin; ${ }^{2}$ Tallaght University Hospital, Dublin; ${ }^{3}$ Coombe Women's and Children's University Hospital, Dublin; ${ }^{4}$ Neonatology, Our Lady's Children's Hospital, Dublin; ${ }^{5}$ National Maternity Hospital, Holles Street, Dublin, Ireland
\end{abstract}

\section{INTRODUCTION}

Haematological abnormalities are common in infants with neonatal encephalopathy (NE) and may be associated with neurodevelopmental outcome. Elevated peripheral leucocyte count is associated with high risk of mortality and neurological disability in infants with NE.

\section{AIM}

To examine any correlation between elevated leucocyte count and adverse neurological outcome in children with NE at school-age

\section{RESULTS}

Significant correlation noted between Bayley's composite cognitive scores (BSID III) in children with NE at 2 years of age and maximum peripheral WCC in the first week of life (Rho $0.4, p$ value $=0.007)($ Table 1$)$

At school-age: The peripheral WCC in NE group was significantly higher than age-matched controls (mean WCC of 9.1 vs $8.1 \times 10^{9} / L$; $p$ value $=<0.02$ ). WCC and neutrophil counts were higher in children with moderate to severe encephalopathy (NE II/III) vs children with mild encephalopathy (NE 0/I) \{mean WCC 9.4 vs $8.5 \times 10^{9} / \mathrm{L} ; \mathrm{p}$ value $=0.07$ and mean neutrophil count 4.3 vs $3.3 \times 10^{9} / \mathrm{L} ; \mathrm{p}$ value $=0.007\}$. ( Figure 1\&2)

No significant difference noted in the haemoglobin $(\mathrm{Hb})$ or platelet levels between the two groups. The WCC and Neutrophil counts did not correlate with school-age developmental outcome on ASQ-3

\section{METHODS}

Early haematological values of neonates with Neonatal Encephalopathy (NE) were correlated with Bayley assessment scores (BSID III) done at 2 years of age $(n=45)$.

We also compared haematological parameters of the same group of children who had NE, at school age $(n=48)$ with age matched controls $(n=52)$ and any associations with Ages and Stages Questionnaire (ASQ-3).

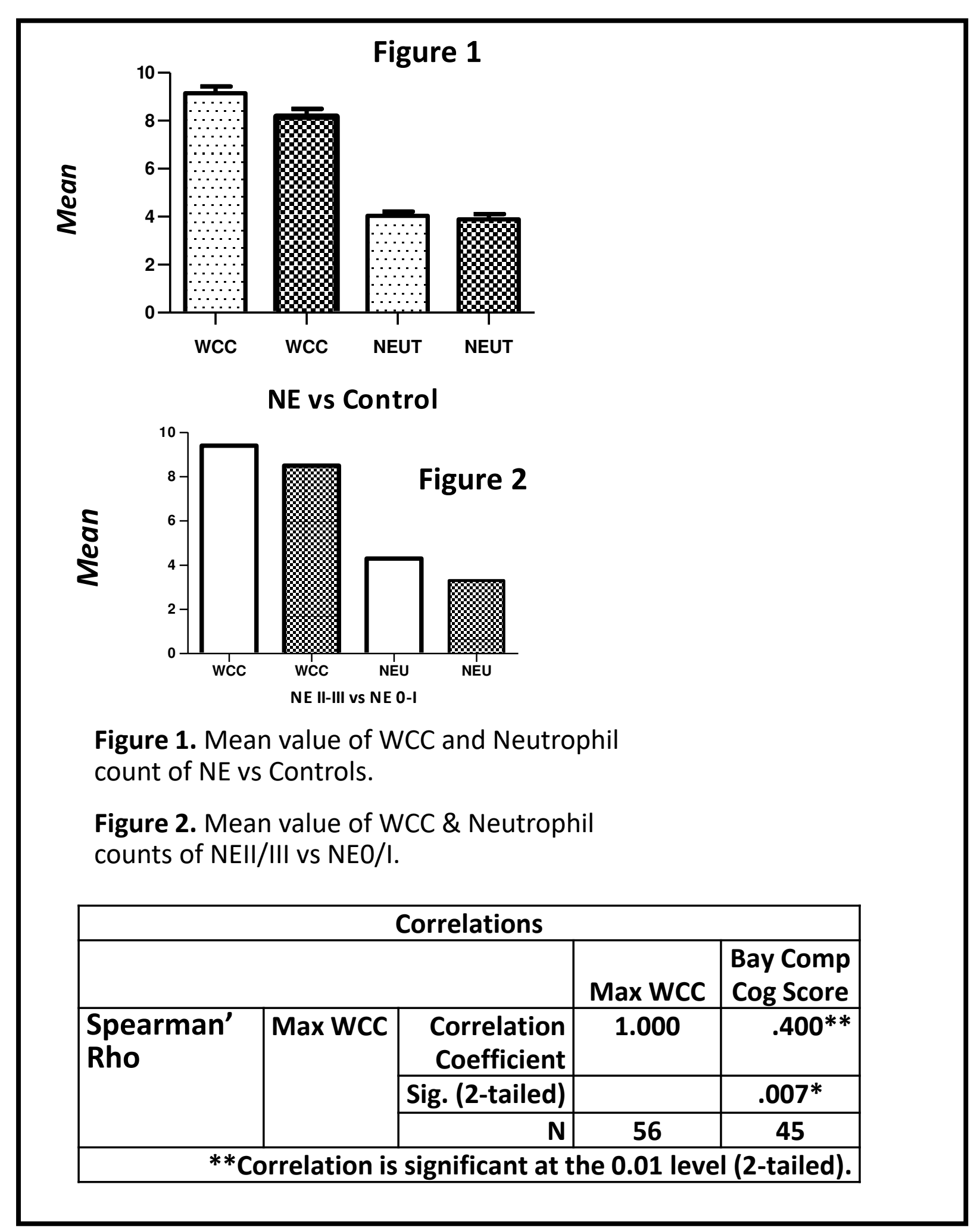

\section{CONCLUSION}

Early white cell count in children with NE predicts abnormal neurodevelopmental outcome. In addition, WCC and Neutrophil counts remain significantly elevated at school-age in children who had NE compared to controls implying a persistently altered systemic inflammatory response.

\section{REFERENCES}

1. Altered circulating leukocytes and their chemokines in a clinical trial of therapeutic hypothermia for neonatal hypoxic ischemic encephalopathy*. Jenkins DD et al 2012, Pediatr Crit Care Med, 14, 786-95.

2. Fleiss $B$, Gressens P. Tertiary mechanisms of brain damage: a new hope for treatment of cerebral palsy? Lancet Neurol2012.

3. Morkos $A A$, Hopper $A O$, Deming DD, et al. Elevated total peripheral leukocyte count may identify risk for neurological disability in asphyxiated term neonates. J Perinatol 2007; 27: 365-370 